\title{
The Stem Cell Potential and Multipotency of Human Adipose Tissue-Derived Stem Cells Vary by Cell Donor and Are Different from Those of Other Types of Stem Cells
}

\author{
Hyun Jin Yang ${ }^{a, c}$ Ki-Joo Kimª,b Min Kyoung Kim ${ }^{a, b}$ Su Jin Lee ${ }^{a}$ \\ Yeon Hee Ryu ${ }^{a}$ b Bommie F. Seo ${ }^{a}$ Deuk-Young Oh ${ }^{a}$ Sang-Tae Ahn ${ }^{a}$ \\ Hee Young Lee ${ }^{c}$ Jong Won Rhie ${ }^{a, b}$ \\ aDepartment of Plastic and Reconstructive Surgery, Seoul St. Mary's Hospital, College of Medicine, and \\ ${ }^{b}$ Department of Molecular Biomedicine, The Catholic University of Korea, and 'Department of Plastic Surgery, \\ Baroyl Plastic Surgery, Seoul, Korea
}

\section{Key Words}

Fat tissue · Adipose tissue-derived stem cells .

Mesenchymal stem cells · Donor · Cell yield ·

Cell proliferation

\begin{abstract}
Human adipose tissue-derived mesenchymal stem cells (ATMSCs) from various sites are applied in tissue engineering and cell therapy. The condition of AT-MSCs depends on the donor's age, body mass index (BMI), and gender. AT-MSCs from 66 human donors were analyzed, and the cells were sorted according to donor age (10-19 years: $\mathrm{n}=1 ; 20-29$ years: $n=5 ; 30-39$ years: $n=12 ; 40-49$ years: $n=22 ; 50-59$ years: $n=12 ; 60-69$ years: $n=9$, and 70 years or older: $n=5$ ), BMI (under 25, 25-30, and over 30), and gender (19 males and 48 females). Additionally, AT-MSCs were compared to bone marrow MSCs and chorionic tissue-derived MSCs. We measured the MSC yield, growth rate, colony-forming units, multipotency, and surface antigens. AT-MSC proliferation was greater in cells isolated from individuals aged less than
\end{abstract} Hyun Jin Yang and Ki-Joo Kim contributed equally to this work.
30 years compared to the proliferation of AT-MSCs from those over 50 years old. BMI was correlated with osteogenic differentiation potency; increased BMI enhanced osteogenesis. Adipogenic differentiation was more strongly induced in cells isolated from donors aged less than 30 years compared to those isolated from other age groups. Also, a BMI above 30 was associated with enhanced adipogenic differ-

\section{Abbreviations used in this paper}

AT-MSCs adipose tissue-derived mesenchymal stem cells BM bone marrow BMI body mass index

BM-MSCs bone marrow mesenchymal stem cells CFU colony-forming units

CFU-F colony-forming unit formation

CT-MSCs chorionic tissue-derived mesenchymal stem cells

DMEM Dulbecco's modified Eagle's medium

ELISA enzyme-linked immunosorbent assay

FBS fetal bovine serum

IRB institutional review board

MSCs mesenchymal stem cells

PBS phosphate-buffered saline

SVF stromal vascular fraction

\section{KARGER}

E-Mail karger@karger.com www.karger.com/cto
(C) 2015 S. Karger AG, Basel

$1422-6405 / 15 / 1996-0373 \$ 39.50 / 0$
Jong Won Rhie, MD

Department of Plastic and Reconstructive Surgery

Seoul St. Mary's Hospital, College of Medicine, The Catholic University of Korea 222 Banpo-daero, Seocho-gu, Seoul 137-701 (Korea)

E-Mail rhie@ catholic.ac.kr 
entiation compared to cells isolated from individuals with a BMI below 25. Bone marrow MSCs were strongly induced to differentiate along both osteogenic and adipogenic lineages, whereas AT-MSCs predominantly differentiated into the chondrogenic lineage. Therefore, the type of regeneration required and variations among potential donors must be carefully considered when selecting MSCs for use in applied tissue engineering or cell therapy.

(c) 2015 S. Karger AG, Basel

\section{Introduction}

Mesenchymal stem cells (MSCs) have recently been isolated from a variety of tissues and are used in many tissue engineering and cell therapy applications. MSCs are not associated with any ethical issues, and immunological rejection is not a problem when the donor and recipient genotypes are identical [Arrigoni et al., 2009]. MSCs can be obtained from bone marrow (BM), the placenta, and the umbilical cord. However, MSCs can only be obtained at low levels from these sources. In contrast, adipose tissue-derived MSCs (AT-MSCs) are readily available in abundance from the stromal vascular fraction (SVF) of tissue in various bodily locations [De Ugarte et al., 2003; Zhe Jin et al., 2008; Lee et al., 2012]. AT-MSCs possess differentiation abilities equivalent to those of BM-MSCs and exhibit multipotent characteristics such as the ability to undergo osteogenic [de Girolamo et al., 2007], chondrogenic [Lin et al., 2005], adipogenic [Gronthos et al., 2001], and neurogenic [Kingham et al., 2007; Lim et al., 2010] differentiation [Cavallo et al., 2011e]. A recent clinical study found that renal transplantation of MSCs, in an effort to ensure donor hyporesponsiveness, enhanced tissue regeneration. Administration of AT-MSCs admixed with hematopoietic stem cells was more effective than the addition of hematopoietic stem cells alone [Vanikar et al., 2010]. Adipose tissue SVF transplantation has been used to induce bone repair [Varma et al., 2007].

Although AT-MSCs are used in cell therapy and tissue engineering, these cells vary depending on the tissue source. The cell yield, the extent of multipotency, and the cell growth rate may differ by cell source [Fraser et al., 2007; Jurgens et al., 2008]. Human adipose tissue can be obtained from several sites including the abdomen, hip, and thigh. Cells from the latter two regions are obtained in higher yields and have greater differentiation capacities than abdominal fat cells [Jurgens et al., 2008]. Colony-forming unit formation (CFU-F) assay is a popular method used to evaluate stem cell capacity, and CFU-F results have varied when the MSC stem cell capacity has been tested. It is thought that donor features influence the characteristics of tissue-derived MSCs. Furthermore, AT-MSCs from the same site exhibit differences in cell yield depending on the harvest depth [Fraser et al., 2007] and vary in osteogenic differentiation potential when cultured in 2- or 3-dimensional environments [Leong et al., 2006]. In addition, AT-MSCs isolated from pregnant women exhibit higher proliferation rates [Ng et al., 2009].

Donor variation in the context of AT-MSC stem cell potential, yield, growth rate, and multipotency was studied. The 66 donors varied in terms of gender, age, and body mass index (BMI). In this study, the effects of other factors were minimized, including the experimental environment (i.e. temperature, humidity, and atmospheric and culture process) and differential operator handling when evaluating the cell yield, CFU-F, growth rate, and multipotency (i.e. adipogenic, osteogenic, and chondrogenic differentiation capacities). Additionally, AT-MSC potential and multipotency were compared to those of BM-MSCs and chorionic tissue-derived MSCs (CTMSCs). Typically, MSCs can be induced into adipogenic, chondrogenic, osteogenic, and neurogenic differentiation. AT-MSCs reportedly exhibit a lower regenerative capacity but a higher differentiation capacity than BMMSCs [Kingham et al., 2007]. In addition, another report found that both AT-MSCs and BM-MSCs exhibited enhanced osteogenic differentiation [Cavallo et al., 2011e]. Due to these findings, variations among donors were explored and we found that AT-MSC capacities may be influenced by different factors.

\section{Materials and Methods}

\section{Collection of AT-, BM-, and CT-MSCs}

MSCs from donors were obtained in accordance with Seoul St. Mary's Hospital of Korea Institutional Review Board (IRB) guidelines (IRB permit No. KC11TNSI0186). AT-MSCs were collected from waste adipose tissues obtained during surgery from 66 donors, and donor data were documented. We analyzed AT-MSCs from 66 human donors by donor age (10-19 years: $\mathrm{n}=1 ; 20-29$ years: $\mathrm{n}=5$; $30-39$ years: $\mathrm{n}=11 ; 40-49$ years: $\mathrm{n}=22 ; 50-59$ years: $\mathrm{n}=12 ; 60-69$ years: $n=9$, and over 70 years: $n=5$ ), BMI (under $25,25-30$, and over 30), and gender (19 males and 48 females). The BMI of 11 patients was excluded due to the absence of height and weight data. Three BM-MSC cell lines (the CMC-MASTER cell line) were purchased from the Catholic Institute of Cell Therapy (CIC; Seoul, Korea). Primary CT-MSCs were obtained from the Seoul St. Mary's Hospital of Korea Department of Obstetrics and Gynecology ( $\mathrm{n}=5$ patients) in accordance with the requirements of the Seoul St Mary's Hospital of Korea IRB (IRB permit No. KC09WZZZ0173). 
Isolation and Culture of AT-MSCs

Adipose tissue was washed 3 times with phosphate-buffered saline (PBS; Wisent Inc., Canada), chopped into small pieces, and digested in PBS with $0.1 \%(\mathrm{w} / \mathrm{v})$ type I collagenase (Sigma-Aldrich, St. Louis, Mo., USA) for $30 \mathrm{~min}$ at $37^{\circ} \mathrm{C}$ in a Celltibator (Medican, Seoul, Korea). The digested adipose tissue was washed 3 times in Dulbecco's modified Eagle's medium (DMEM; Gibco-BRL, Grand Island, N.Y., USA) with 10\% (v/v) fetal bovine serum (FBS; Wisent Inc.) and $1 \%(\mathrm{v} / \mathrm{v})$ of an antibiotic-antimycotic solution (Gibco$\mathrm{BRL}$ ). The sample was centrifuged for $3 \mathrm{~min}$ at $350 \mathrm{~g}$. The supernatants were discarded and the cell pellets were suspended in DMEM and passed through a strainer with a $100-\mu \mathrm{m}$ pore diameter (Becton Dickinson, San Jose, Calif., USA). The filtered cells were centrifuged for $3 \mathrm{~min}$ at $350 \mathrm{~g}$ and the supernatants were discarded. The cell pellets were suspended in DMEM. The cells were counted using a hemocytometer, seeded in culture dishes at a cell density of 7,000 cells $/ \mathrm{cm}^{2}$, and incubated at $37^{\circ} \mathrm{C}$ under $5 \%(\mathrm{v} / \mathrm{v})$ $\mathrm{CO}_{2}$. CT-MSCs were cultured in minimum essential medium alpha with $10 \%(\mathrm{v} / \mathrm{v}) \mathrm{FBS}, 1 \%(\mathrm{v} / \mathrm{v})$ of an antibiotic-antimycotic solution, and $1 \%(\mathrm{w} / \mathrm{v})$ GlutaMAX ${ }^{\mathrm{TM}}$ (Gibco-BRL). When the cell monolayers reached $80-90 \%$ confluence, the cells were subcultured after treatment with trypsin-EDTA (Gibco BRL). Both the cell viability and the growth rate were evaluated at passages 3-5. All of the culture medium was replaced every third day.

\section{Morphology and Growth Identification}

To assess the growth rates (doubling times) of MSCs, cells were seeded in 48-well plates at a cell density of 9,000 cells/well and incubated for 3 days at $37^{\circ} \mathrm{C}$ under $5 \%$ (v/v) $\mathrm{CO}_{2}$ in the appropriate culture media. We measured optical densities using a Cell Count Kit-8 (CCK-8; Dojindo, Kumamoto, Japan) solution mixed with a 10 -fold excess of DMEM. The culture medium in the plates was exchanged for this solution, and the MSCs were then incubated for $2 \mathrm{~h}$ at $37^{\circ} \mathrm{C}$ under $5 \%(\mathrm{v} / \mathrm{v}) \mathrm{CO}_{2}$. Next, the supernatants $(100 \mu \mathrm{l})$ were transferred into the wells of a fresh 96-well plate and the absorbance values were read at $450 \mathrm{~nm}$ using an enzyme-linked immunosorbent assay (ELISA) reader (Spectramax PLUS384; Molecular Devices, Sunnyvale, Calif., USA).

\section{CFU-F Assay}

To measure CFUs, MSCs were seeded into $55-\mathrm{cm}^{2}$ culture dishes $\left(1,000\right.$ cells) and incubated for 3 weeks at $37^{\circ} \mathrm{C}$ under $5 \%(\mathrm{v} / \mathrm{v})$ $\mathrm{CO}_{2}$ in the appropriate culture media. Next, the culture medium was discarded and the cells were washed 3 times with PBS. The cells were fixed in methanol (Duksan, Ansan, Korea) for $5 \mathrm{~min}$, and the methanol was then removed. To stain fixed MSCs, a solution of $0.5 \%(\mathrm{w} / \mathrm{v})$ crystal violet (Sigma-Aldrich) was added for $5 \mathrm{~min}$ and then washed out with PBS and distilled water. The stained cells were dried at room temperature and colonies were counted. A colony was defined as a cluster of more than 40 cells. The culture medium was replaced every third day.

Multipotency: Osteogenesis, Chondrogenesis, and Adipogenesis MSCs (passages 3-5) were subjected to osteogenic, adipogenic, and chondrogenic differentiation. Cells (4,000 cells/well) were seeded in 12-well plates and incubated in the appropriate medium at $37^{\circ} \mathrm{C}$ under $5 \%(\mathrm{v} / \mathrm{v}) \mathrm{CO}_{2}$. When the cells reached $70 \%$ confluence, the culture medium was changed to differentiation medium. The cells were then incubated for 2 weeks at $37^{\circ} \mathrm{C}$ under $5 \%(\mathrm{v} / \mathrm{v})$ $\mathrm{CO}_{2}$. The adipogenic and chondrogenic differentiation media were from a Stempro Adipogenic Differentiation Kit (Gibco-BRL) and a Stempro Chondrogenic Differentiation Kit (Gibco-BRL), respectively. The osteogenic differentiation medium used was: DMEM supplemented with $10 \%(\mathrm{v} / \mathrm{v}) \mathrm{FBS}, 1 \%(\mathrm{v} / \mathrm{v})$ of an antibiotic-antimycotic solution, $0.1 \mathrm{~mm}$ dexamethasone (Sigma-Aldrich), $10 \mathrm{~mm}$ glycerol-2-phosphate (Sigma-Aldrich), and $37.5 \mu \mathrm{l} /$ $\mathrm{ml}$ ascorbic acid-phosphate (Sigma-Aldrich). The differentiation media was changed every fifth day.

\section{Staining: Adipogenic, Osteogenic, and Chondrogenic \\ Differentiation}

Adipogenic differentiation was assessed by Oil Red O staining. Cells were washed with PBS, fixed in absolute propanediol (SigmaAldrich) for $6 \mathrm{~min}$ at room temperature, and stained with $0.5 \%$ $(\mathrm{w} / \mathrm{v})$ Oil Red O solution (Sigma-Aldrich) for $1 \mathrm{~h}$ at room temperature. After 3 gentle washes with $85 \%(\mathrm{v} / \mathrm{v})$ propanediol, the cells were treated with absolute propanediol for $1 \mathrm{~min}$ and then washed with PBS and distilled water. Stained cells were suspended in PBS and photographed under an Olympus CKX41 microscope (NY Microscope Co., Hicksville, N.Y., USA). To quantify staining, the stain was eluted into $4 \%(\mathrm{v} / \mathrm{v})$ Nonidet ${ }^{\circledR} \mathrm{P}-40$ (Amresco, Solon, Ohio, USA), and the solutions were diluted with isopropanol prior to measurement of absorbance at $520 \mathrm{~nm}$ using an ELISA reader.

To measure osteogenic differentiation, the extent of calcium deposition was assessed by staining with Alizarin Red S. Cultured cells were washed twice with PBS and fixed in $10 \%(\mathrm{v} / \mathrm{v})$ formalin (Sigma-Aldrich) for $10 \mathrm{~min}$ at room temperature. After washing, cells were treated with 2\% (w/v) Alizarin Red S (Sigma-Aldrich) for $10 \mathrm{~min}$, suspended in PBS, and photographed under an Olympus CKX41 microscope. To quantify staining, the stain was eluted into a solution of $10 \%(\mathrm{w} / \mathrm{v})$ cetylpyridinium chloride (Sigma-Aldrich). Absorbance was read at $550 \mathrm{~nm}$ using an ELISA reader.

Chondrogenic differentiation was analyzed using Alcian Blue staining. Cultured cells were washed with distilled water and fixed in $0.1 \mathrm{M} \mathrm{HCl}$ for $5 \mathrm{~min}$ at room temperature. A $1 \%(\mathrm{w} / \mathrm{v})$ solution of Alcian Blue (Sigma-Aldrich) was added and the cells were incubated for $24 \mathrm{~h}$ in the dark. The cells were then treated with $0.1 \mathrm{M}$ $\mathrm{HCl}$ (Daejung, Busan, Korea) for $5 \mathrm{~min}$ and washed with PBS. Cells were next treated with a $0.1 \%(\mathrm{w} / \mathrm{v})$ solution of Nuclear Fast Red (Sigma-Aldrich) for $3 \mathrm{~min}$ and washed with PBS. The stained cells were suspended in PBS and photographed under an Olympus CKX41 microscope. To quantify staining, the stain was eluted into a solution of $6 \mathrm{M}$ guanidine hydrochloride (Sigma-Aldrich), and the absorbance was read at $620 \mathrm{~nm}$ using an ELISA reader.

\section{Cell Membrane Antigen Identification: Flow Cytometry}

MSCs (passage 4) were subjected to flow cytometric analysis. The cells were trypsinized and resuspended in Hanks' balanced salt solution (Wisent Inc.) with $2 \%$ (v/v) FBS. The cells were next incubated with monoclonal fluorescein isothiocyanate-conjugated antibodies against CD90, CD13, human lymphocyte antigen class II (HLA-DR; Becton Dickinson), and CD105 (AbD Serotec, Oxford, UK) and PE-conjugated antibodies against CD34, CD73, CD45, and CD146 (Becton Dickinson) for $30 \mathrm{~min}$ on ice in the dark. Cells stained with anti-isotype IgG1 served as a negative control. After washing with Hanks' balanced salt solution, the cells were fixed in $0.5 \%(\mathrm{w} / \mathrm{v})$ paraformaldehyde (Sigma-Aldrich) and analyzed via flow cytometry (Becton Dickinson). Cell surface markers were detected and quantitated using Summit software, version 5.2 (Beckman Coulter, Brea, Calif., USA). 
Table 1. AT-MSCs from 66 patients

\begin{tabular}{|c|c|c|c|c|c|c|c|c|c|}
\hline No. & Gender & $\begin{array}{l}\text { Age, } \\
\text { years }\end{array}$ & $\begin{array}{l}\text { Weight, } \\
\text { kg }\end{array}$ & $\begin{array}{l}\text { Height, } \\
\mathrm{cm}\end{array}$ & No. & Gender & $\begin{array}{l}\text { Age, } \\
\text { years }\end{array}$ & $\begin{array}{l}\text { Weight, } \\
\mathrm{kg}\end{array}$ & $\begin{array}{l}\text { Height, } \\
\mathrm{cm}\end{array}$ \\
\hline 1 & $\mathrm{~F}$ & 52 & 59.02 & 150.9 & 35 & $\mathrm{~F}$ & 46 & 58 & 154 \\
\hline 2 & $\mathrm{~F}$ & 57 & 55 & 153 & 36 & $\mathrm{~F}$ & 63 & 64 & 163 \\
\hline 3 & $\mathrm{~F}$ & 47 & 51 & 155 & 37 & $\mathrm{~F}$ & 62 & 47 & 150 \\
\hline 4 & $\mathrm{~F}$ & 44 & 63.8 & 156.1 & 38 & $\mathrm{~F}$ & 47 & 74.5 & 155 \\
\hline 5 & M & 22 & 95 & 164 & 39 & $\mathrm{~F}$ & 47 & 77 & 155.1 \\
\hline 6 & $\mathrm{~F}$ & 55 & 68 & 160 & 40 & $\mathrm{~F}$ & 38 & 101 & 183 \\
\hline 7 & $\mathrm{~F}$ & 30 & 109.6 & 164 & $\overline{41}$ & $\mathrm{~F}$ & 52 & 58 & 160 \\
\hline 8 & $\mathrm{~F}$ & 59 & 49 & 159 & 42 & M & 72 & 46 & 161 \\
\hline 9 & $\mathrm{~F}$ & 38 & 66.2 & 156.2 & 43 & M & 55 & 71 & $\mathrm{~N} / \mathrm{A}$ \\
\hline 10 & $\mathrm{~F}$ & 38 & 101 & 183 & 44 & $\mathrm{~F}$ & 31 & 55 & N/A \\
\hline 11 & $\mathrm{~F}$ & 48 & 56.3 & 157.4 & 45 & $\mathrm{~F}$ & 49 & 61.5 & 163.3 \\
\hline 12 & $\mathrm{~F}$ & 25 & 37.5 & 157 & 46 & $\mathrm{~F}$ & 41 & 73 & 164 \\
\hline 13 & $\mathrm{~F}$ & 61 & 42 & 158 & 47 & $\mathrm{~F}$ & 41 & 73 & 164 \\
\hline 14 & $\mathrm{M}$ & 26 & $\mathrm{~N} / \mathrm{A}$ & N/A & 48 & $\mathrm{~F}$ & 41 & 73 & 164 \\
\hline 15 & $\mathrm{~F}$ & 36 & 54.4 & 155 & 49 & $\mathrm{~F}$ & 25 & 62 & $\mathrm{~N} / \mathrm{A}$ \\
\hline 16 & $\mathrm{~F}$ & 54 & 51.25 & 158.7 & 50 & $\mathrm{~F}$ & 67 & 67 & N/A \\
\hline 17 & $\mathrm{~F}$ & 67 & 53 & 149 & $\overline{51}$ & $\mathrm{M}$ & 72 & 49 & 160 \\
\hline 18 & $\mathrm{M}$ & 39 & $\mathrm{~N} / \mathrm{A}$ & N/A & 52 & M & 42 & 49 & 160 \\
\hline 19 & $\mathrm{~F}$ & 67 & 53 & 149 & 53 & M & 72 & 49 & 160 \\
\hline 20 & $\mathrm{~F}$ & 41 & 82.8 & 172.5 & 54 & M & 72 & 49 & 160 \\
\hline 21 & $\mathrm{~F}$ & 36 & 57.25 & 150.9 & 55 & $\mathrm{~F}$ & 45 & 71 & 155 \\
\hline 22 & $\mathrm{~F}$ & 39 & 60.2 & 165.4 & 56 & M & 45 & 71 & N/A \\
\hline 23 & $\mathrm{M}$ & 61 & 65 & 164.5 & 57 & $\mathrm{~F}$ & 37 & 54 & $\mathrm{~N} / \mathrm{A}$ \\
\hline 24 & $\mathrm{M}$ & 49 & 89.4 & 167.9 & 58 & M & 55 & 71 & N/A \\
\hline 25 & $\mathrm{~F}$ & 64 & 61 & 161 & 59 & M & 55 & 71 & N/A \\
\hline 26 & $\mathrm{~F}$ & 43 & 72 & 162 & 60 & $\mathrm{~F}$ & 39 & 53 & 158 \\
\hline 27 & $\mathrm{~F}$ & 40 & 52.55 & 157.4 & 61 & $\mathrm{~F}$ & 43 & 70 & 163 \\
\hline 28 & M & 18 & 76 & 184 & 62 & $\mathrm{~F}$ & 57 & 66 & 160 \\
\hline 29 & $\mathrm{~F}$ & 22 & 52 & 158 & 63 & M & 47 & 70 & 168 \\
\hline 30 & $\mathrm{~F}$ & 43 & 57 & N/A & 64 & $\mathrm{~F}$ & 52 & 62 & 163 \\
\hline 31 & $\mathrm{M}$ & 72 & 49 & 160 & 65 & M & 37 & 81 & 177 \\
\hline 32 & $\mathrm{~F}$ & 68 & 55 & 160 & 66 & $\mathrm{~F}$ & 56 & 54.3 & 161.9 \\
\hline 33 & $\mathrm{M}$ & 40 & 63 & 173 & \multirow{2}{*}{\multicolumn{5}{|c|}{$\mathrm{M}=$ Male $; \mathrm{F}=$ female $; \mathrm{N} / \mathrm{A}=$ not available. }} \\
\hline 34 & $\mathrm{~F}$ & 44 & 53 & 155 & & & & & \\
\hline
\end{tabular}

\section{Results}

Interindividual Variation in AT-MSCs

Adipose tissues were collected from 66 donors categorized in terms of BMI, gender, and age (table 1). The BMI of 11 patients was excluded due to the absence of the patients' height and weight. Thus, the BMI was analyzed in 55 donors.

\section{MSC Yield from Adipose Tissue}

AT-MSCs were isolated from adipose tissue obtained from various sites on the 66 donors. The MSC yield was much greater for donors aged less than 30 years compared to older donors; the yield gradually fell as the donor age rose. Patients aged 10-29 years yielded twice the number of cells compared to those aged 50-59 years ( $p<0.0001$; fig. 1a). The yield was not affected by gender or BMI (fig. 1b, c). Patients with a BMI below 25 yielded more cells than those with a BMI of 25-29 (p = 0.05).

\section{Proliferation of MSCs from Adipose Tissue}

We examined AT-MSC proliferation by donor age, gender, and BMI. Cells from donors aged less than 30 years proliferated readily and those from donors over 50 years of age proliferated slowly ( $<<0.0001$; fig. $2 b)$. The proliferation rates of primary cells and those of cells at all passages up to passage 4 were similar (fig. 2a). AT-MSCs 
from males proliferated more rapidly than those from females ( $p<0.05$; fig. $2 \mathrm{c}$ ). The BMI was not associated with the proliferation rate (fig. $2 b$ ).

\section{CFU-F Assay}

AT-MSC self-renewal ability was evaluated using a CFU-F assay and did not vary by age, gender, or BMI (fig. 3a-c).

\section{Cell Membrane Antigens of AT-MSCs}

AT-MSCs were positive for stem cell markers (CD13, CD73, CD90, and CD105). Conversely, AT-MSCs were negative for hematopoietic markers (CD34 and CD35) and an immune cell marker (HLA-DR). Surface marker expression levels did not vary by donor age, gender, or BMI (fig. 4a-c). Positive markers were expressed in at least $80 \%$ of cells, and negative markers were expressed in less than $6 \%$ of cells.

Multipotency of AT-MSCs: Osteogenic and Adipogenic Differentiation

AT-MSCs were evaluated in terms of their capacity to exhibit osteogenic and adipogenic differentiation. The extent of osteogenic differentiation fell somewhat as the donor age rose, but this trend did not reach statistical significance (fig. 5a). Osteogenic differentiation was not affected by donor gender (fig. 5b). However, an increased BMI was significantly associated with a rise in the extent of osteogenic differentiation $(\mathrm{p}<0.005$; fig. 5c). Adipogenic differentiation was more strongly induced in cells from donors under rather than over 30 years of age (fig. 6a). Additionally, a BMI over 30 was associated with a higher level of adipogenic differentiation than that noted in those with a BMI below 25 (fig. 6c). Gender did not affect the extent of adipogenic differentiation (fig. 6b).

\section{Multipotency of AT-, BM-, and CT-MSCs}

The multipotencies of various types of MSCs, including AT-, BM-, and CT-MSCs, were evaluated in terms of osteogenic, chondrogenic, and adipogenic differentiation (fig. 7a). BM-MSCs could be strongly induced to differentiate into the osteogenic and adipogenic lineage, and AT-MSCs could be induced to differentiate into the chondrogenic lineage. CT-MSCs appeared to differentiate less readily than AT- and BM-MSCs (fig. $7 \mathrm{~b}-\mathrm{d}$ ).
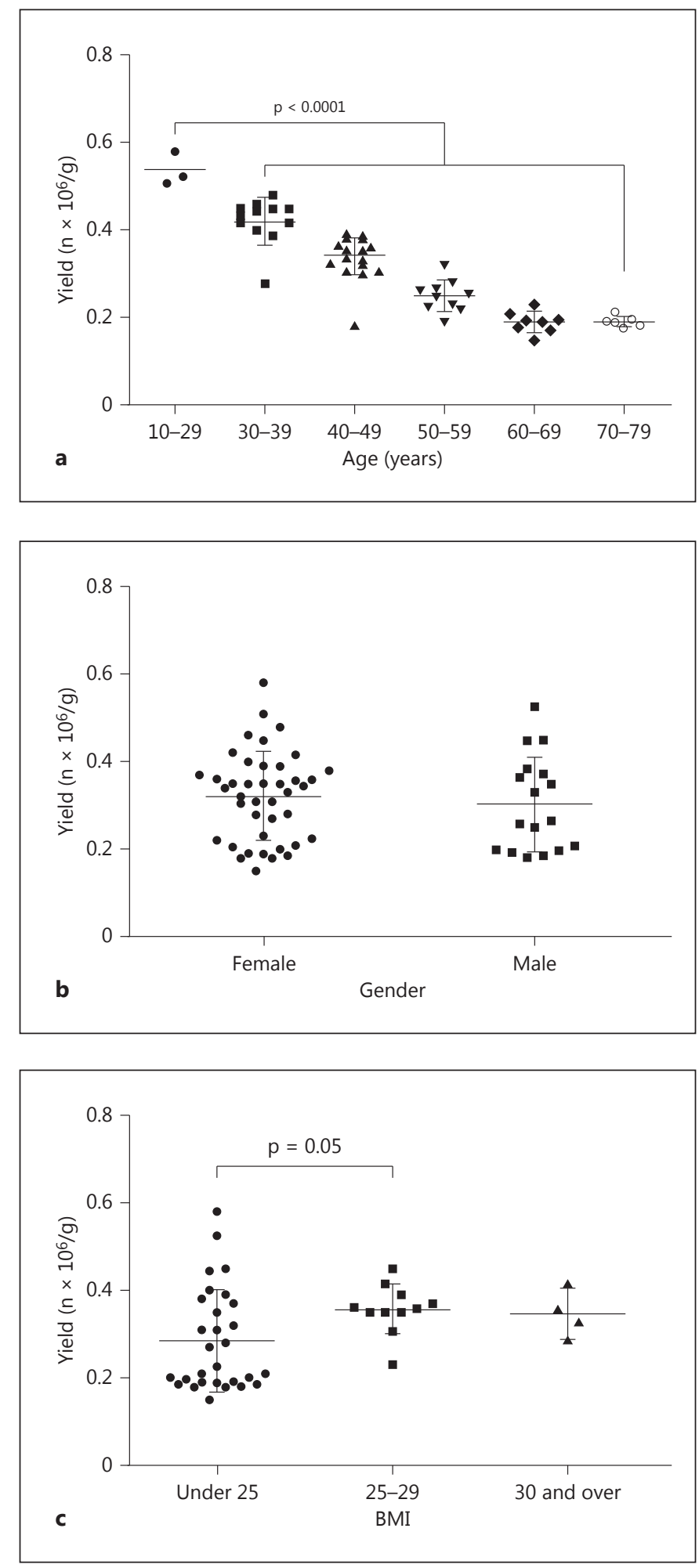

Fig. 1. Human AT-MSCs were isolated from adipose tissue obtained from 66 donors. a The AT-MSC yield of donors less than 30 years of age $(\mathrm{p}<0.0001)$ was considerably greater. $\mathbf{b}$ The ATMSC yield did not differ by gender. c The AT-MSC yield was increased for donors with a BMI $>25$ but $<29$. 

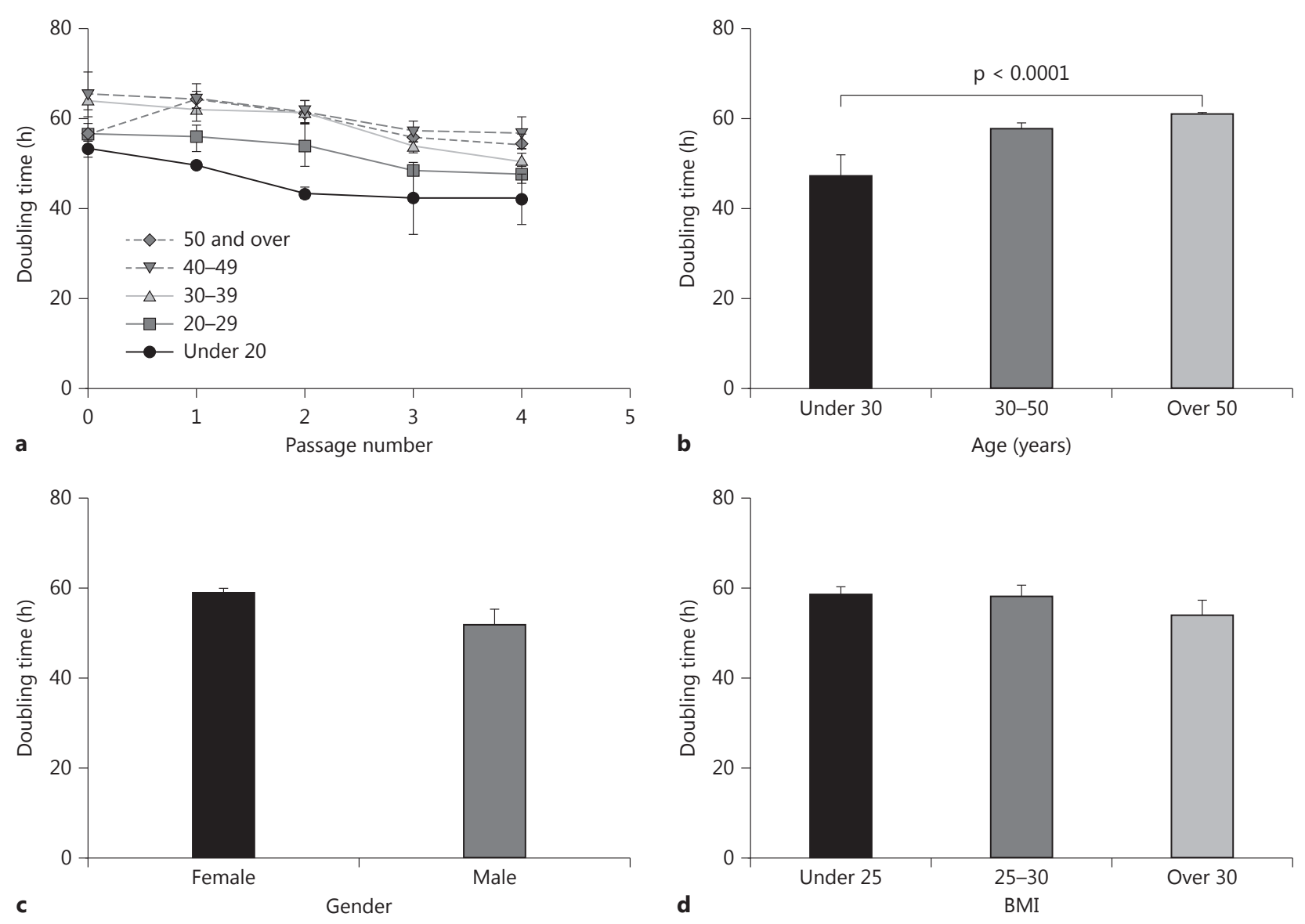

Fig. 2. AT-MSC proliferation doubling time. a The doubling time decreased with each passage (0-4). b The doubling time increased with donor age. AT-MSCs isolated from donors less than 30 years of age had an increased proliferation rate compared to those from donors over 50 years of age $(\mathrm{p}<0.0001)$. c The AT-MSC doubling time did not differ by donor gender. $\mathbf{d}$ The AT-MSC doubling time not differ by donor BMI.

\section{Discussion}

Adipose tissue is abundant and easy to acquire; MSCs therein can be used in tissue engineering and stem cell therapy [Fraser et al., 2008; Gimble et al., 2011]. Donor factors, including height, weight, gender, and age, influence the properties of AT-MSCs. Many studies do not consider the AT-MSC isolation site or donor factors, but several studies have shown that the properties of ATMSCs depend on such parameters [Aust et al., 2004; de Girolamo et al., 2009; Faustini et al., 2010]. In addition, the SVF may be affected by both the adipose tissue preparation method and the chopping regimen [Mojallal et al., 2008].
We examined AT-MSCs from 66 donors and observed that the cell properties varied. Possible influences of BMI, age, and gender on cell yield, proliferative capacity, stem cell properties, and multipotency were explored. Furthermore, the multipotency of AT-MSCs was compared with that of BM- and CT-MSCs under the same experimental conditions.

Faustini et al. [2010] reported that neither donor age nor BMI affected the cell yield when preparing AT-MSCs from 125 donors. De Girolamo et al. [2009] found that AT-MSCs from young donors were obtained in higher yields compared to those from older donors; our results were similar. The cell yield and cell ability may differ due to varied methods used to separate cells from tissue and 

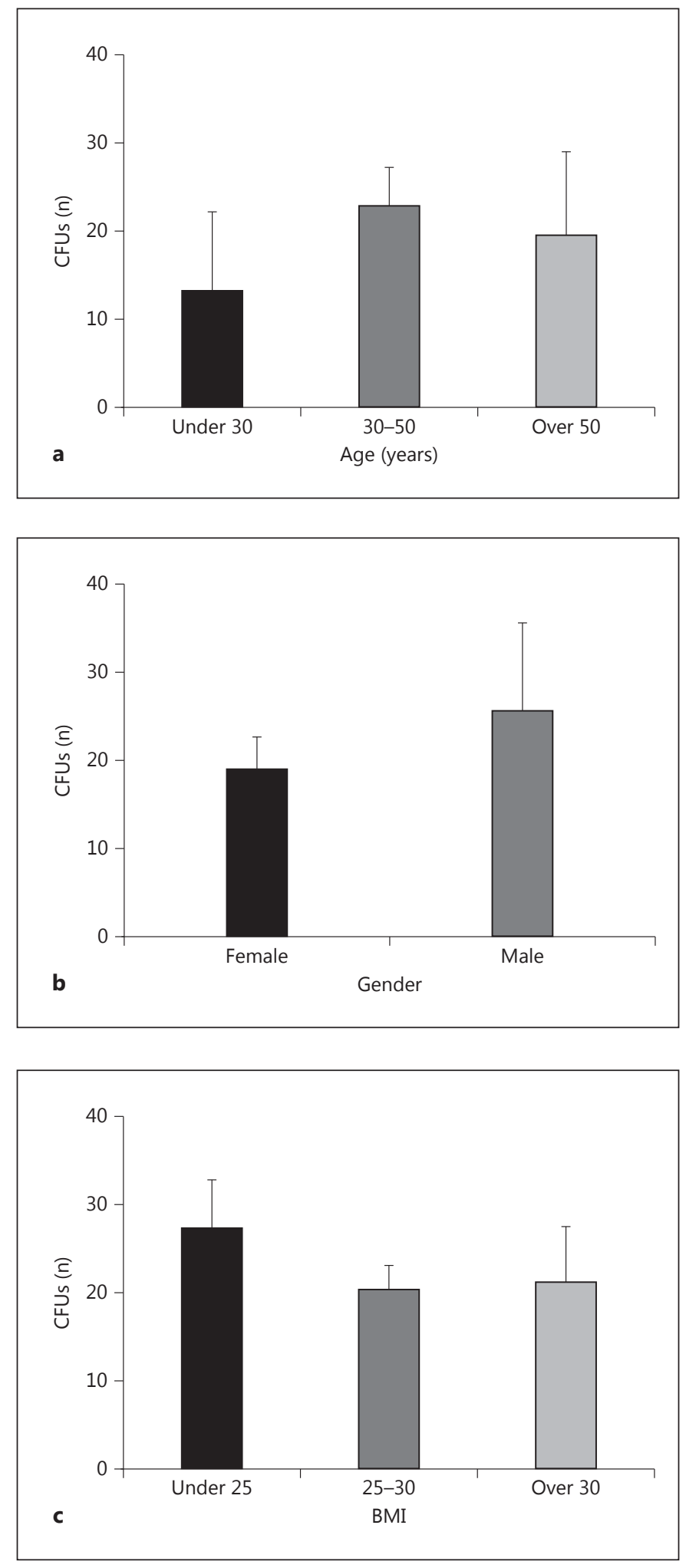

Fig. 3. AT-MSC colony forming units (CFUs) compared according to donor characteristics. AT-MSC CFUs classified by donor age (a), donor gender (b), and donor BMI (c). CFUs did not differ by age, gender, or BMI.

Stem Cell Variability Varies by Donor Characteristics and Cell Type
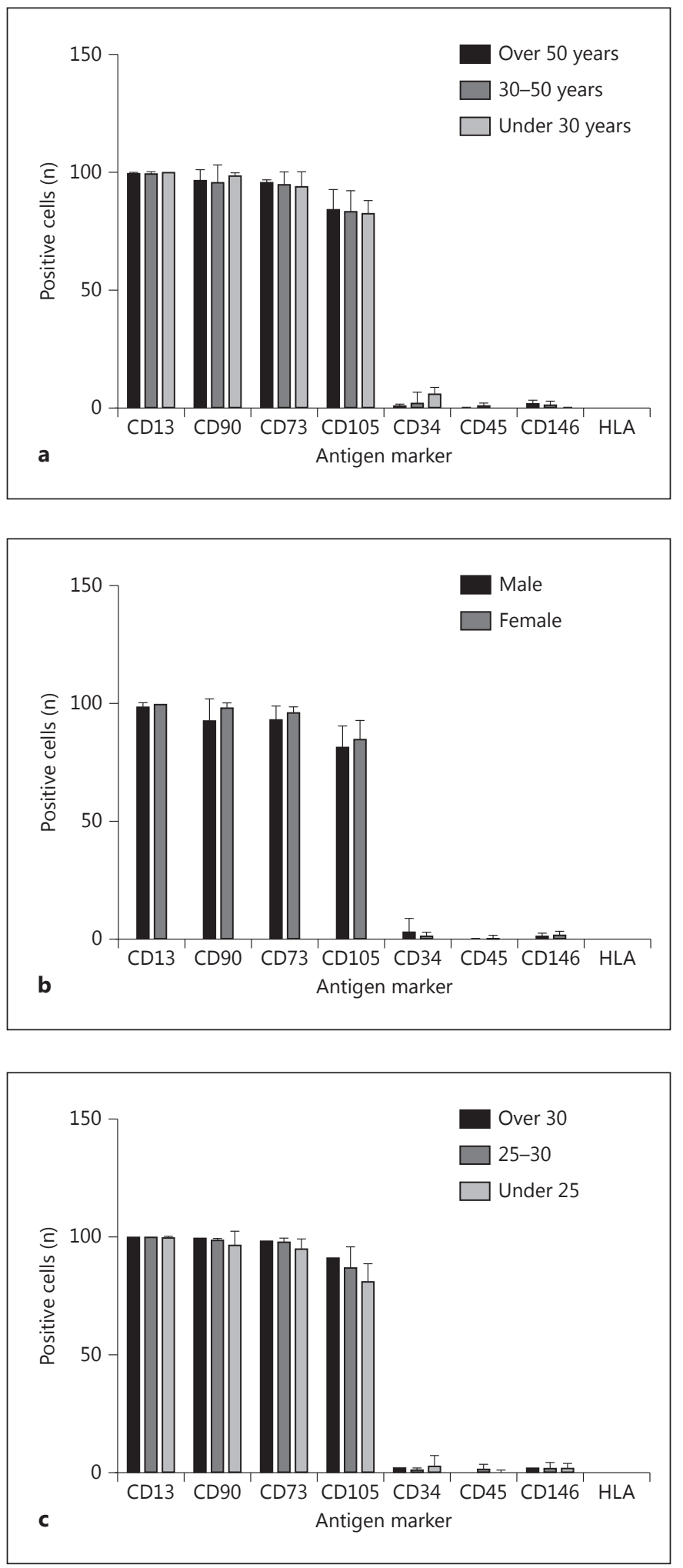

Fig. 4. Flow cytometry of AT-MSCs compared according to donor characteristics. Flow cytometry of AT-MSCs classified by donor age (a), donor gender (b), and donor BMI (c). Flow cytometry results did not differ by age, gender, or BMI. 

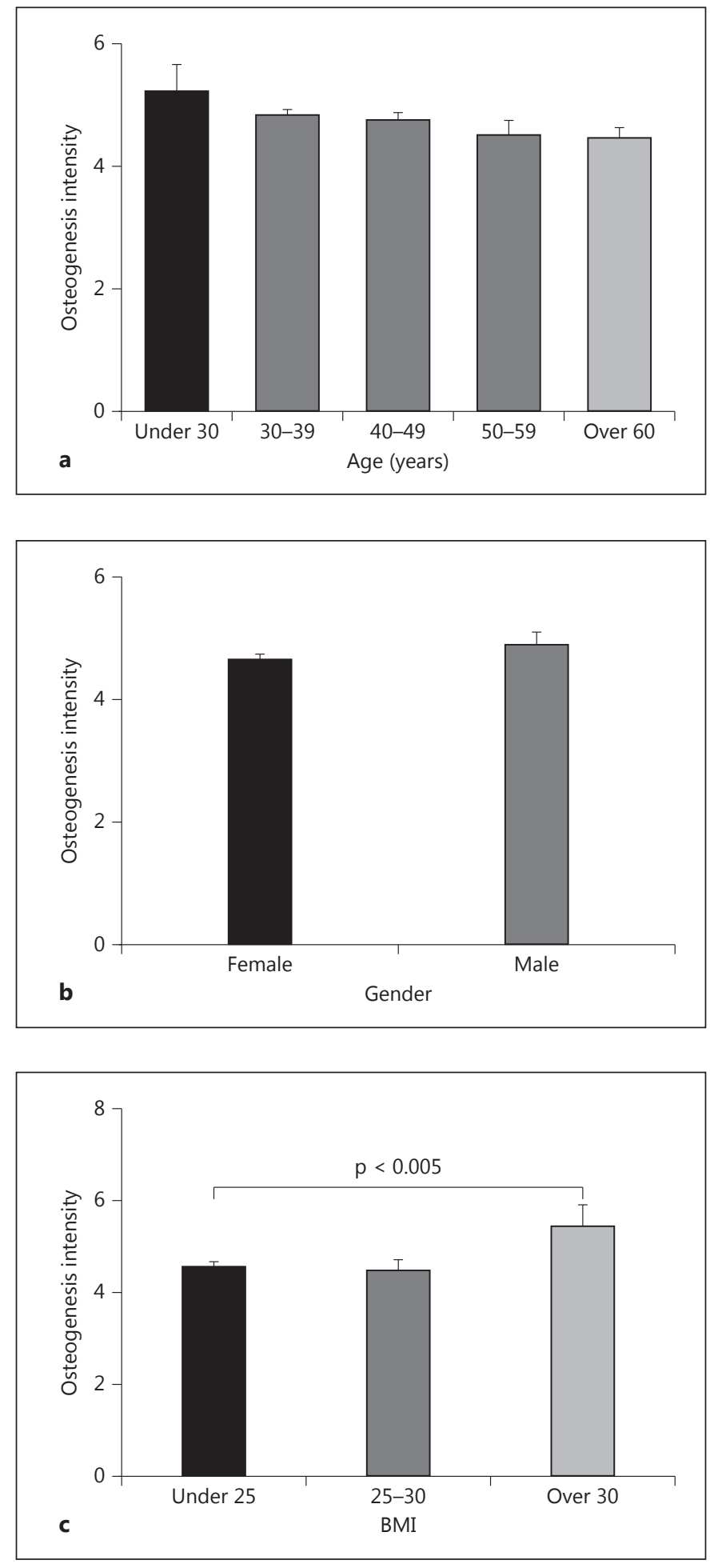

Fig. 5. Osteogenic differentiation of AT-MSCs compared according to donor characteristics. a The osteogenic differentiation of AT-MSCs did not differ by donor age. $\mathbf{b}$ The osteogenic differentiation of AT-MSCs did not differ by donor gender. c The osteogenic differentiation of AT-MSCs was increased in donors with a BMI $>30$ compared to donors with a BMI $<25(\mathrm{p}<0.005)$. the primary culture protocols used. Recent reports have been contradictory regarding whether or not BMI and donor age affect the cell yield [Aust et al., 2004; Griesche et al., 2010]. Differences in tissue separation and chopping methods may explain these differences [Oedayrajsingh-Varma et al., 2006; Griesche et al., 2010].

AT-MSCs from 66 donors were evaluated under identical conditions. The cell yield fell significantly with increasing donor age, and the cell growth was more vigorous when cells were isolated from younger rather than older donors. Neither the cell yield nor the growth rate was affected by BMI. CFU-F was decreased when the age of the donors increased, while proliferation was increased. We compared the connectivity of the CFU and proliferation rate and ensured the relevance of these and the BMI. CFU-F was low when the proliferation ability was high in donors less than 30 years of age. Additionally, the proliferation and CFU-F ability were decreased when a high BMI resulted in a high cell yield.

Cell surface antigens were analyzed by flow cytometry to demonstrate the stem cell capacity of AT-MSCs. In a previous study, AT-MSCs isolated from the hip formed twice the number of colonies compared to cells isolated from the abdomen [Fraser et al., 2007]. We observed no significant differences in cells from different isolation sites. However, we confirmed that age, gender, and BMI influenced cellular properties [Jurgens et al., 2008; Bieback et al., 2009]. CD13 and CD90 were expressed on the surfaces of AT-MSCs, and CD45 and HLA-DR were absent [Aust et al., 2004]. In a previous study, CD73 and CD105 were present and CD34 was absent [Baptista et al., 2009]. Therefore, all AT-MSCs expressed CD13, CD73, CD90, and CD105 but did not express hematopoietic markers [Jurgens et al., 2008; Bieback et al., 2009; Griesche et al., 2010; Goedecke et al., 2011]. Adipose tissue SVF contains hematopoietic cells [Varma et al., 2007; Faustini et al., 2010], but these cells are eliminated upon subculture (typically, by passage 3 ).

The multipotency of AT-MSCs was explored by inducing osteogenic and adipogenic differentiation. A previous study found that the extent of adipogenic differentiation was not affected by donor age, although osteogenic differentiation was more strongly induced in cells from younger rather than older donors [de Girolamo et al., 2009]. We found that the extent of osteogenic differentiation was significantly greater in cells from donors with a BMI greater than 25 as compared to those from donors with BMI below 25. In addition, osteogenic differentiation decreased somewhat with donor age, although this association did not reach statistical significance. Adipo- 


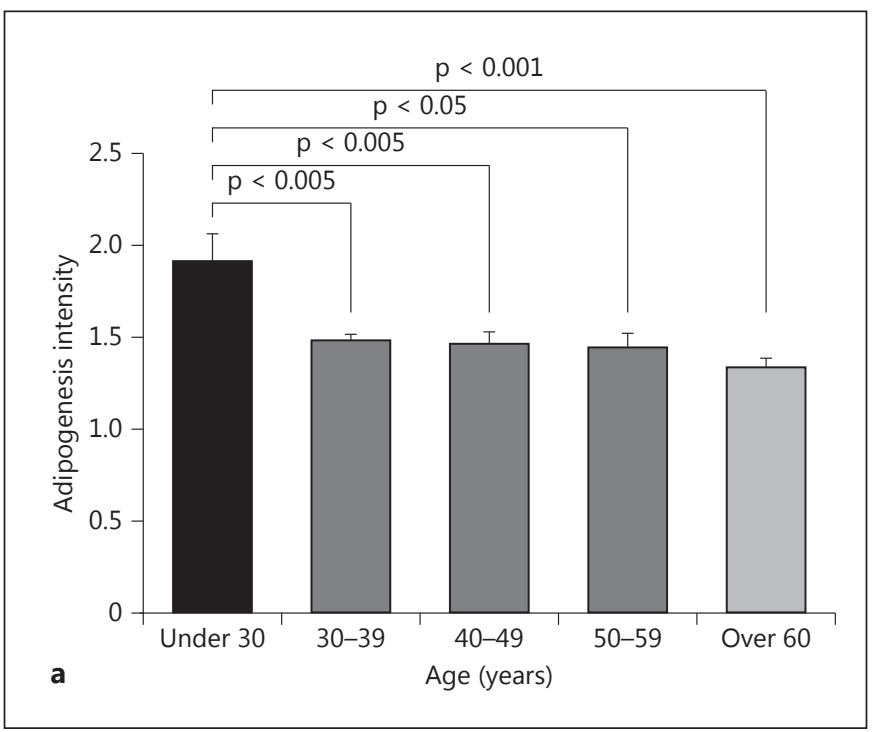

Fig. 6. Adipogenic differentiation of AT-MSCs compared according to donor characteristics. a The adipogenic differentiation of AT-MSCs was increased in donors under 30 years of age compared to donors aged $30-39$ years ( $\mathrm{p}<0.005), 40-49$ years $(\mathrm{p}<0.005)$, $50-59$ years $(\mathrm{p}<0.05)$, and over 60 years $(\mathrm{p}<0.001)$. b The adipogenic differentiation of AT-MSCs did not differ by donor gender. c The adipogenic differentiation of AT-MSCs was increased in donors with a BMI $>30$ compared to donors with a BMI $<25$ ( $\mathrm{p}<$ $0.001)$ or $25-30(\mathrm{p}<0.05)$.

genic differentiation was induced to a greater extent in cells from donors under 30 years of age than in cells from donors over 30 years of age, and adipogenic differentiation increased with elevated BMI. Neither osteogenic nor adipogenic differentiation was affected by donor gender.

AT-MSC ability was examined by comparing the multipotency of BM-MSCs and CT-MSCs. BM-MSCs engaged in osteogenic and adipogenic differentiation more readily than did CT- or AT-MSCs. Furthermore, AT-MSCs readily differentiated along the chondrogenic lineage. CTMSCs did not readily differentiate. Therefore, MSCs to be used in tissue engineering must be carefully selected with regard to the type of differentiation required and variation in properties caused by BMI, age, and gender.

Stem Cell Variability Varies by Donor Characteristics and Cell Type
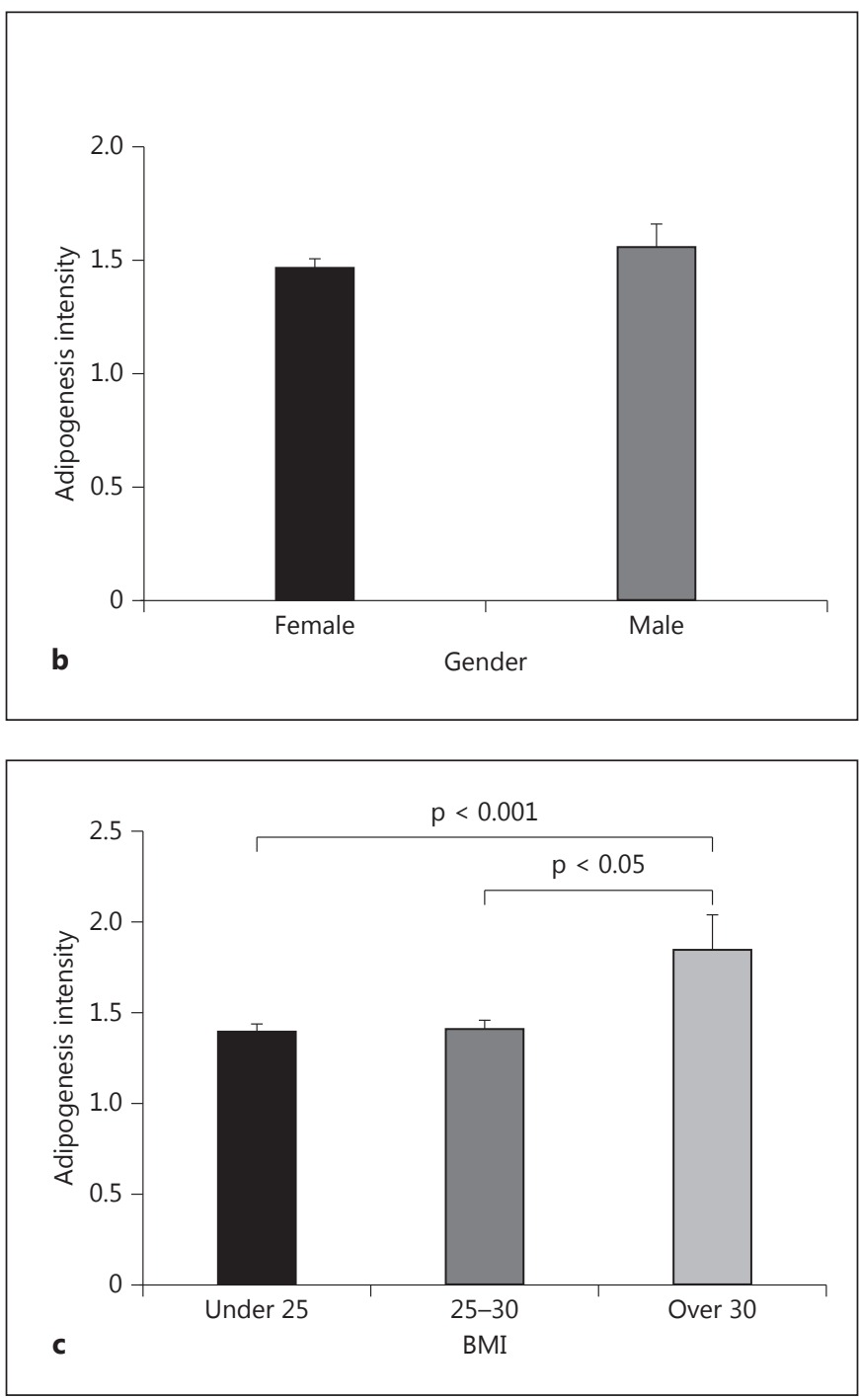

The cell yield of donors aged less than 30-39 years was considerably greater, and cells from donors under 29 years of age proliferated readily compared to cells from those over 40 years of age. An increased BMI was significantly associated with an increased osteogenic differentiation of AT-MSCs, and a BMI over 30 was associated with a higher level of adipogenic differentiation than a BMI below 25. Therefore, MSCs must be selected after careful consideration of the type of regeneration required, and variations among potential donors should be examined when MSCs are to be used in applied tissue engineering or cell therapy. 
CT-MSCS
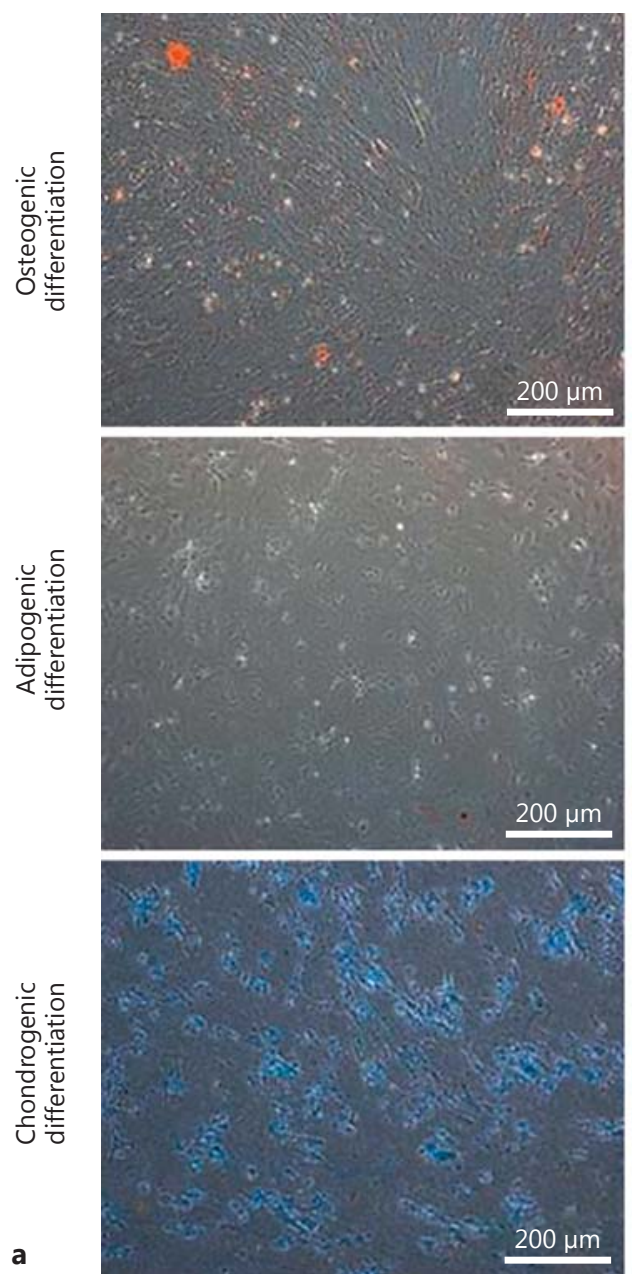

AT-MSCs
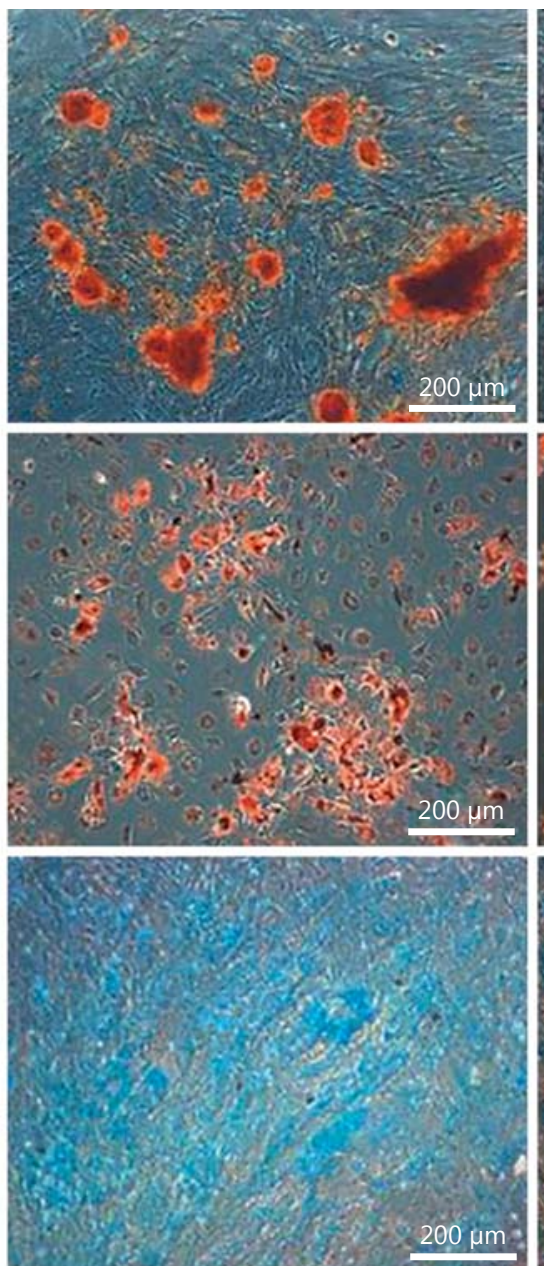

BM-MSCs
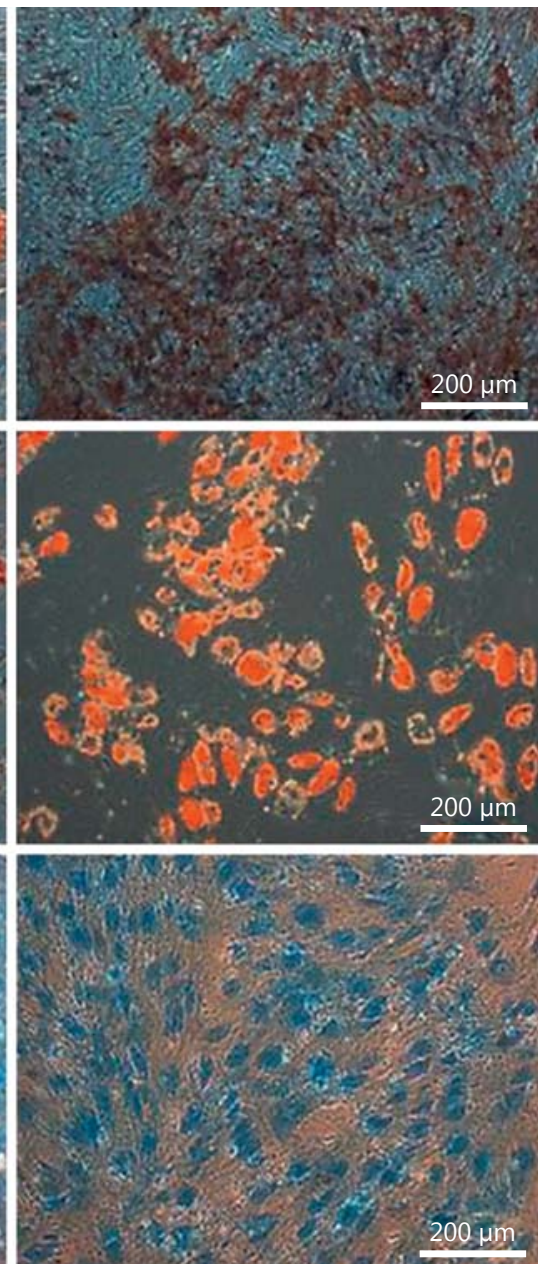

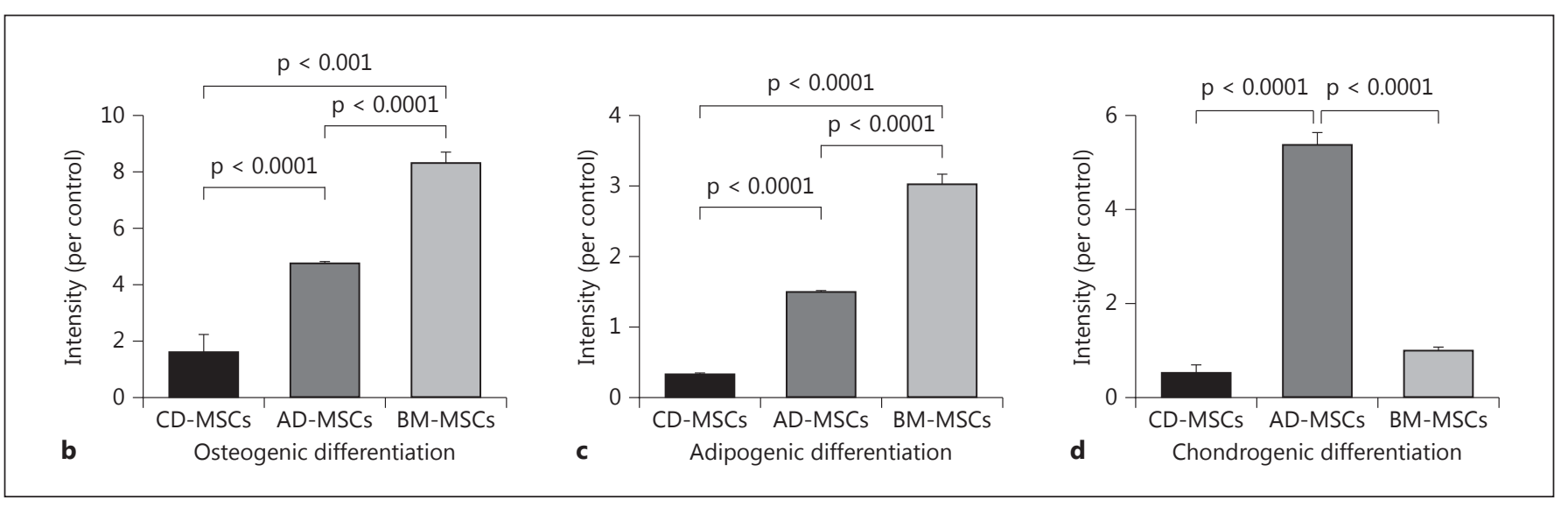

Fig. 7. Osteogenic, adipogenic, and chondrogenic differentiation of MSCs from various origins. a Photomicrographs of differentiated MSCs. b Quantification of the osteogenic differentiation of MSCs from various origins after 14 days of culture. BM-MSCs were strongly induced to differentiate into the osteogenic lineage compared to CT- and AT-MSCs $(\mathrm{p}<0.001)$. c Quantification of the adipogenic differentiation of MSCs from various origins after
14 days of culture. BM-MSCs were strongly induced to differentiate into the adipogenic lineage compared with CT- and AT-MSCs $(\mathrm{p}<0.0001)$. $\mathbf{d}$ Quantification of the chondrogenic differentiation of MSCs from various origins after 14 days of culture. AT-MSCs were strongly induced to differentiate into the chondrogenic lineage compared with CT- and BM-MSCs $(\mathrm{p}<0.0001)$. 


\section{Acknowledgments}

This research was supported by a grant for 'the Center for Evaluating Next-Generation Stem Cell-based Therapeutics (CENST)' supported by the National Institute of Food and Drug Safety Evaluation, an affiliate of the Ministry of Food and Drug Safety (14172 CENST 974) and a Seoul R\&BD Program of the Seoul government of Korea (No. SS110011C0211601).

\section{References}

Arrigoni, E., S. Lopa, L. de Girolamo, D. Stanco, A.T. Brini (2009) Isolation, characterization and osteogenic differentiation of adipose-derived stem cells: from small to large animal models. Cell Tissue Res 338: 401-411.

Aust, L., B. Devlin, S.J. Foster, Y.D. Halvorsen, K. Hicok, T. du Laney, A. Sen, G.D. Willingmyre, J.M. Gimble (2004) Yield of human adipose-derived adult stem cells from liposuction aspirates. Cytotherapy 6: 7-14.

Baptista, L.S., R.J. do Amaral, R.B. Carias, M. Aniceto, C. Claudio-da-Silva, R. Borojevic (2009) An alternative method for the isolation of mesenchymal stromal cells derived from lipoaspirate samples. Cytotherapy 11: 706-715.

- Bieback, K., A. Hecker, A. Kocaomer, H. Lannert, K. Schallmoser, D. Strunk, H. Kluter (2009) Human alternatives to fetal bovine serum for the expansion of mesenchymal stromal cells from bone marrow. Stem Cells 27: 23312341.

Cavallo, C., C. Cuomo, S. Fantini, F. Ricci, P.L. Tazzari, E. Lucarelli, D. Donati, A. Facchini, G. Lisignoli, P.M. Fornasari, B. Grigolo, L. Moroni (2011e) Comparison of alternative mesenchymal stem cell sources for cell banking and musculoskeletal advanced therapies. J Cell Biochem 112: 1418-1430.

de Girolamo, L., S. Lopa, E. Arrigoni, M.F. Sartori, F.W. Baruffaldi Preis, A.T. Brini (2009) Human adipose-derived stem cells isolated from young and elderly women: their differentiation potential and scaffold interaction during in vitro osteoblastic differentiation. Cytotherapy 11: 793-803.

de Girolamo, L., M.F. Sartori, W. Albisetti, A.T. Brini (2007) Osteogenic differentiation of human adipose-derived stem cells: comparison of two different inductive media. J Tissue Eng Regen Med 1: 154-157.

De Ugarte, D.A., K. Morizono, A. Elbarbary, Z. Alfonso, P.A. Zuk, M. Zhu, J.L. Dragoo, P. Ashjian, B. Thomas, P. Benhaim, I. Chen, J. Fraser, M.H. Hedrick (2003) Comparison of multi-lineage cells from human adipose tissue and bone marrow. Cells Tissues Organs 174: 101-109.

-Faustini, M., M. Bucco, T. Chlapanidas, G. Lucconi, M. Marazzi, M.C. Tosca, P. Gaetani, M. Klinger, S. Villani, V.V. Ferretti, D. Vigo, M.L. Torre (2010) Nonexpanded mesenchymal stem cells for regenerative medicine: yield in stromal vascular fraction from adipose tissues. Tissue Eng Part C Methods 16: 15151521.

Fraser, J.K., I. Wulur, Z. Alfonso, M. Zhu, E.S. Wheeler (2007) Differences in stem and progenitor cell yield in different subcutaneous adipose tissue depots. Cytotherapy 9: 459467.

Fraser, J.K., M. Zhu, I. Wulur, Z. Alfonso (2008) Adipose-derived stem cells. Methods Mol Biol 449: 59-67.

Gimble, J.M., W. Grayson, F. Guilak, M.J. Lopez, G. Vunjak-Novakovic (2011) Adipose tissue as a stem cell source for musculoskeletal regeneration. Front Biosci (Schol Ed) 3: 69-81. Goedecke, A., M. Wobus, M. Krech, N. Munch, K. Richter, K. Holig, M. Bornhauser (2011) Differential effect of platelet-rich plasma and fetal calf serum on bone marrow-derived human mesenchymal stromal cells expanded in vitro. J Tissue Eng Regen Med 5: 648-654.

Griesche, N., W. Luttmann, A. Luttmann, T. Stammermann, H. Geiger, P.C. Baer (2010) A simple modification of the separation method reduces heterogeneity of adipose-derived stem cells. Cells Tissues Organs 192: 106-115.

Gronthos, S., D.M. Franklin, H.A. Leddy, P.G. Robey, R.W. Storms, J.M. Gimble (2001) Surface protein characterization of human adipose tissue-derived stromal cells. J Cell Physiol 189: 54-63.

Jurgens, W.J., M.J. Oedayrajsingh-Varma, M.N. Helder, B. Zandiehdoulabi, T.E. Schouten, D.J. Kuik, M.J. Ritt, F.J. van Milligen (2008) Effect of tissue-harvesting site on yield of stem cells derived from adipose tissue: implications for cell-based therapies. Cell Tissue Res 332: 415-426.

Kingham, P.J., D.F. Kalbermatten, D. Mahay, S.J. Armstrong, M. Wiberg, G. Terenghi (2007) Adipose-derived stem cells differentiate into a Schwann cell phenotype and promote neurite outgrowth in vitro. Exp Neurol 207: $267-$ 274.

Lee, J.H., K.H. Lee, M.H. Kim, J.P. Kim, S.J. Lee, J. Yoon (2012) Possibility of undifferentiated human thigh adipose stem cells differentiating into functional hepatocytes. Arch Plast Surg 39: 593-599.

Leong, D.T., W.M. Khor, F.T. Chew, T.C. Lim, D.W. Hutmacher (2006) Characterization of osteogenically induced adipose tissue-derived precursor cells in 2-dimensional and 3-dimensional environments. Cells Tissues Organs 182: 1-11.

Lim, J.H., L. Boozer, C.L. Mariani, J.A. Piedrahita, N.J. Olby (2010) Generation and characterization of neurospheres from canine adipose tissue-derived stromal cells. Cell Reprogram 12: 417-425.

Lin, Y., E. Luo, X. Chen, L. Liu, J. Qiao, Z. Yan, Z. Li, W. Tang, X. Zheng, W. Tian (2005) Molecular and cellular characterization during chondrogenic differentiation of adipose tissue-derived stromal cells in vitro and cartilage formation in vivo. J Cell Mol Med 9: 929-939.

Mojallal, A., C. Auxenfans, C. Lequeux, F. Braye, O. Damour (2008) Influence of negative pressure when harvesting adipose tissue on cell yield of the stromal-vascular fraction. Biomed Mater Eng 18: 193-197.

Ng, L.W., S.K. Yip, H.K. Wong, G.H. Yam, Y.M Liu, W.T. Lui, C.C. Wang, K.W. Choy (2009) Adipose-derived stem cells from pregnant women show higher proliferation rate unrelated to estrogen. Hum Reprod 24: 1164 1170.

Oedayrajsingh-Varma, M.J., S.M. van Ham, M Knippenberg, M.N. Helder, J. Klein-Nulend, T.E. Schouten, M.J. Ritt, F.J. van Milligen (2006) Adipose tissue-derived mesenchymal stem cell yield and growth characteristics are affected by the tissue-harvesting procedure. Cytotherapy 8: 166-177.

- Vanikar, A.V., H.L. Trivedi, A. Feroze, K.V. Kanodia, S.D. Dave, P.R. Shah (2010) Effect of co-transplantation of mesenchymal stem cells and hematopoietic stem cells as compared to hematopoietic stem cell transplantation alone in renal transplantation to achieve donor hypo-responsiveness. Int Urol Nephrol 43: 225 232

Varma, M.J., R.G. Breuls, T.E. Schouten, W.J. Jurgens, H.J. Bontkes, G.J. Schuurhuis, S.M. van Ham, F.J. van Milligen (2007) Phenotypi$\mathrm{cal}$ and functional characterization of freshly isolated adipose tissue-derived stem cells. Stem Cells Dev 16: 91-104.

Zhe Jin, Y.-Q.G., X.-C. Qin, J. Zhang, Y.-C. Zhu, G.-T. Lin, T.F. Lue, Z.-C. Xin (2008) Biodegradable poly(lactic-co-glycolic acid) maxpol-T/S as nobel scaffold for adipose derived stem cells and fibroblast growth in vitro. Tissue Eng Regen Med 5: 869-876.
Stem Cell Variability Varies by Donor Characteristics and Cell Type 